\title{
The Health Communication Orientation of Poor Community in Rural Areas on West Bandung District, West Java
}

\author{
Asep Suryana, Tinne Silvana, Dedi Rumawan Erlandia \\ Manajemen Komunikasi, Fakultas Ilmu Komunikasi \\ Universitas Padjadjaran \\ Bandung Indonesia \\ asepsuryanakachya@yahoo.com
}

\begin{abstract}
The long-term goal of this research is to form a health-oriented communication model for the poor people in West Bandung District (Kabupaten Bandung Barat), West Java. The specific purpose is to know about perception of very poor household (Rumah Tangga Sangat Miskin/RTSM) of health problem. In this study the researchers attempted to reveal the phenomenon of poor health communication by expressing their perceptions of various aspects related to health problems that they are facing daily. Therefore, the method used in this research is survey method with descriptive approach. Data analysis is done by interpreting data that have been processed, presented in single table or cross table. Interpretation in addition to referring of existing data, is also reinforced by the results of interviews, observations, studies of previous research, and concepts that connected with the phenomenon studied. The results showed perception of very poor households (RTSM) on health problem, was in medium category.
\end{abstract}

Keywords-communication health development model; very poor household; perception

\section{INTRODUCTION}

Health is a very important aspect in life and human life. Healthy living is everyone's dream. Even in condition of poor, when sick, one will seek to heal his body from the pain. In response to health, everyone will associate it with the state of his body when he suffers illness. Health becomes very important when humans can feel how troublesome when the body becomes weak because of illness. Health is a physical, mental, and social well-being and not just a state of illness or weakness [1]]. In Law no. 36 of 2009 [2] on health argued that health is a healthy state, physically, mentally, spiritually, and socially which enables everyone to live productively socially and economically. Health is all efforts and actions of a person to keep, maintain, and improve its own level of health within the limits of its ability, in order to get the joy of life and have the best performance to work [3].

Central Bureau of Statistics (BPS) notes that based on data from 2000 to 2011, the distribution of poverty in Indonesia shows the number of poor people in rural areas more than in urban areas [4]. The poverty rate in rural areas reaches 63.2 percent, while urban poverty reaches 36.8 percent. According to BPS, poverty in rural areas is caused, among other things, by the low level of education, the large number of rural population who become farm laborers because of lack of land ownership, the number of children is quite a lot, and others. Meanwhile, urban poverty, among others, is caused by limited workplace, limited human resource quality. Poverty in West Bandung area according to social department in West Bandung regency has reached 55.000 families. There are still quite a lot of very poor families in West Bandung regency, whose life is very limited economically.

Poverty in West Bandung can be relative, absolute, structural and cultural poverty. Relative poverty is related to the state of society which is very limited in its ability to earn a decent income because of the uneven development conducted the government. Absolute poverty is a condition of society that cannot afford to fulfill minimum basic needs. Meanwhile, the structural and cultural poverty is the poor condition of society caused by the structure and culture as well as customs in a region that binds the society in it, so it does not develop [5].

The poor condition experienced by the community has implications on various limitations of opportunities to obtain facilities, including health facilities. Therefore, the purpose of this study was to determine the perception of very poor households (RTSM) on health problems.

\section{RESEARCH METHOD}

The method used in this research is descriptive. The data obtained through the filling questionnaire in which aspects have been designed in such a way that can reveal the phenomenon studied. The population for this study is the Poor Household that resides in West Bandung Regency. Based on data from the Central Bureau of Statistics of West Bandung regency [6], are as many as 153 Heads of Families. Samples were taken by nonrandom by purposive sampling technique. There are 3 sub-districts taken RTSM as sample, that is District Ngamprah, Cililin and Cisarua, where each region was taken 20 respondents. The sample size is 60 respondents.

Technique of collecting data was done by questionnaires, interviews, observation and documentation study. Questionnaires before being used was, as a trial, distributed to 20 people who have the same characteristics with respondents. 
The results of the instrument test show that the questionnaire meets the requirements of validity and reliability.

Data analysis technique is done by looking at the tendency of data either based on single table or cross tabulation. Based on these trends then conducted analysis and interpretation based on synthesis between research data, theory used, concepts used, previous research, interviews, observation results, and data from relevant documents.

\section{RESULT AND DISCUSSION}

The respondents of this study consisted of 45 men (75\%) and 15 women $(25 \%)$. Based on the age of respondents, the most respondents aged 35 to 39 years, are 18 people (30\%) and the rest are variations from the age of 25 to 54 years. Based on their education, it appears that most of the respondents are junior high school (not finished) and graduated from elementary school, as many as 31 people (51.7\%). Other variations are respondents with no school, elementary school is not finished, junior high school is not finished, high school is not finished, and graduated from senior high school. As for the average, the average monthly income ranges from 500 thousand rupiah to $\mathrm{Rp} 2$ million. This shows that the economic condition of respondents is very limited. Such conditions are caused by many factors, including the type of work they are engaged in, the low level of education, the wage rates received in principle do not refer to the minimum regional wage (UMR), but are based on the usual wage given in the region, the low bargaining power of the given wage, helplessness in the face of the rich, people having a lot of money, resignation to the fate encountered, and various other aspects. Distribution of data for children respondents showed that most of the respondents had children from 1 to 2 people are 46 people (76.7\%), the rest varied, between have no children, until having 4 children. In relation to the work of the respondents shows that the work of respondents in this study varied. However, most of them are farm laborers, reaching 33.3 percent. This is reasonable because this research area is an agricultural area. The next most are drivers and maids and factory workers.

\section{A. The Orientation of Very Poor Household to Health Problems}

The poor, the same as the other humans in general, view healthy and health as a very important aspect of life and human life. Through this research it was revealed that RTSM has quite varied perception related to health problems. The components that construct perceptual models of very poor household health problems (RTSM) include:

- Perceptions of health and treatment, revealing what respondents think based on their experiences in medicinal efforts when themselves and their families are ill. In this aspect, the result of the research shows that respondents' approval reach 48.3 percent. So when the respondents and their families are sick, part of the family tries to treat it in the usual way, not just let it go. This means that the illness experienced by the respondents and or their families are always associated with the drug that should be consumed as the antidote, so that the body condition to improve again.
- Perception of healthy body information. when there are family members who are sick, usually the whole family want to know which parts of the body are feeling sick. This happens naturally and each family member thinks about what medication is supposed to treat the disease. In the minds of the surviving family members is the "medicine stall" (a drug that is sold freely in stalls), which is considered suitable with the pain experienced by the family members. Based on the results of the research that has been done shows that most respondents, namely 48.3 percent blame approval of family reaction to the pain experienced by one of its members.

- Perceptions of alternative healing. When a family member is sick and does not recover with a drug bought from a "stall", the next healing effort is to go to the community health center (puskesmas), go to paraji, or go to alternative medication. Despite a very minimal financial condition, but when a family member is sick, they force themselves to get the money, either in the form of selling existing items that can be sold, or borrowing from the people who feel touched, even when under pressured, they borrow from moneylenders (rentenir). In the treatment process, sometimes the medication given Puskesmas does not give a healing effect on the disease. For healing the disease later by using alternative medication. The reason is as an effort because chemical drugs from Puskesmas have no effect. Based on research conducted showed that 55 percent of respondents expressed their approval for alternative medication and felt the recovery from the treatment.

- Perception of doctors' ability. In the context of this study, what is meant by the belief in the ability of doctors in curing the sick is the respondents' perception related to their belief in the ability of doctors in healing the sick rather than to the paraji/dukun and alternative medicine. At the study site, not a few people who still believe in the treatment of paraji dukun and alternative medicine. The results showed 46.6 percent of respondents expressed his agreement on the ability of doctors in treating the sick. Respondents assume that doctors have the knowledge, insight and skills that no doubt in treating the sick. Doctors have the right ways to diagnose diseases that exist in the body of the sick. Doctors also have thoughts and solutions and decisions to establish the drugs and therapies given to their patients.

- Perception of the important value of health problems. Perceptions of the important value of health problems are the perceptions of respondents related to family attention to health issues, whether concerning illness, body health, home health, including environmental health. Although in poor condition, respondents have an interest to always discuss actual health issues. The results of this study showed 60 percent of respondents expressed their agreement to the statement that they are always talking about health problems and recognize how important that health in life. Although under limited circumstances, where the state of the house and 
surrounding neighborhoods appear slums, they attempt to avoid aspects that can cause illness, such as washing rice with clean water, as well as drinking water, they are trying hard to come from a clean water source. Similarly associated with bathing, washing dishes, washing clothes, defecating and others, they seek in a healthy condition.

- Perceptions of treatment orientation. What is meant by medication orientation when there is a pain in this study is the perception of respondents associated with efforts made when facing illness conditions in the family. The effort varies, depending on the source of the illness experienced. Some are based on family habits that are hereditary, some are asking for help to people who are considered to be able to cure diseases with prayer, there are also some who immediately buy drugs that are sold in stall (warung), and others. The results showed 55 percent of respondents gave their consent to the statement about health orientation. So respondents generally agree that if the sick, both themselves and their families are done first understand the pain part perceived, then take appropriate action.

- Perceptions of alternative medication. In everyday life, there are citizens whose orientation of treatment not only to the doctor, but also looking for various alternatives that are expected to cure the disease. They went to have a medication to a medical doctor, but not healed. So in an effort to get his healing, they were trying to find another way. Alternative medication, which is an alternative way to cure diseases, many manifold/kinds. Various offers of healing in various ways are often promoted, whether through newspapers, brochures, banners and others. The results obtained through alternative treatments vary, some are recovered, but some others get their illness getting worse. Through this study, the data obtained show that 53.3 percent of respondents expressed their approval of statements relating to alternative medication. Another perception associated with alternative medication is that alternative medication is more practical, not bureaucratic, cheaper, not scolded by nurses, can be done at any time, and the disease can be cured if get the 'right' alternative medication .

- Perception towards having treatment to Puskesmas. If there is a sick person at home, then the family usually ask how he feels, and immediately take him to the community health center (Puskesmas). In this context, puskesmas is the main reference when the family gets sick. The family believes in the function and role of puskesmas in curing diseases. The results showed that 48.3 percent of respondents expressed their approval of the statement when sick or his family was sick, then the Puskesmas became the main reference. Puskesmas have been known by the community for a long time. Currently Puskesmas services are improving, although within certain limits are still complained by the public. For medical treatment of RTSM is very dependent on the family and Puskesmas. The main reason, much free of charge, although sometimes there are drugs that must be purchased outside the health center.

- Perception of the importance of disease discussion. The pleasure of talking about health with the neighbors referred to this study is the respondents' perception of topics discussed with neighbors in everyday life. Of the various topics discussed, then one of them is related to health, both related to illness and disease, diseases suffered by others, diseases that are much talked about by everyone in the mass media, as well as severe diseases, suffered by famous artists. The results showed that 56.7 percent of respondents expressed their agreement on statements relating to the importance of discussion about health and/or illness.

- Perceptions of health related to the management of life and the environment. Health and the management of life and environment referred to in this study is the respondents' perception related to their view of the link between human health experienced by the way they lived their life and its relation to the environment. The daily chats that occur in society rarely in particular discuss the interrelationships between the three aspects, but the phrases that appear sometimes also indicate the existence of community thinking about the pattern of life, diet, mindset, and patterns of environmental treatment. The results showed that 51.6 percent of respondents expressed their approval for the importance of health care in relation to the management of life and the environment.

- Perceptions of health information needs. The need for health information in the context of this research is the respondents' effort as a citizen to know the illness they have, by asking the doctors of puskesmas that are considered experts and qualified in the health field. Usually uttered to the doctor, in addition to complaints of pain suffered, as well as other aspects around the disease, such as the feeling of nausea, headaches, eyes blazing, difficult to breathe, and others. In addition, there are also citizens who only express complaints only their disease without talking other aspects. The results showed that 50 percent of respondents expressed their agreement on the need for health information. Health information is needed by the respondents when they are faced with the condition: (a) when there is a sick family member, (b) there is a sick relative (eg. brother, sister), (c) when there is a sick neighbor, (d) when others ask about health and does not know about it, (e) there is information from others, such as from neighbors, family, and others about illness or other health problems that are not understood.

- Perception of health information through mass media. What is meant by the level of attention to health information through mass media is the perception of respondents related to the efforts made to obtain information from various sources of mass media, such as television, radio, and computer. Although the respondents of this study are very poor households, but in daily life they also seek to get a variety of 
information from television and radio, either from their own belongings, or join neighbors who have it. The results showed that 43.3 percent of respondents expressed their agreement that they received health information from various mass media, such as radio and television. Although they do not have radio and television, but at certain times they have the opportunity to watch and or listen from neighbors'.

The categorization for the perception of very poor households (RTSM) on health issues is based on the scores of respondents in answering questionnaires. In this research, categorization is made into three classifications, namely high, medium and low category. Scores include high categories if they are at intervals between 44.2 and 60.2; including the moderate category if it is at intervals between 28.1 and 44.1 and belongs to a low category if it is at intervals between 12 and 28 .

In Table 1 . the results are categorized based on the table which appears that the largest percentage is in the medium category, which are 65.0 percent, as low category 18.3 percent and high category 16.7 percent.

TABLE I. THE CATEGORIZATION FOR THE PERCEPTION OF VERY POOR HOUSEHOLDS (RTSM) ON HEALTH ISSUES

\begin{tabular}{|l|l|c|c|}
\hline No. & Category & Frequence & Percentage \\
\hline 1. & Height & 10 & 16.7 \\
\hline 2. & Medium & 39 & 65.0 \\
\hline 3. & Low & 11 & 18.3 \\
\hline & Total & 60 & 100.0 \\
\hline
\end{tabular}

As for health communication model orientation of very poor household in Kabupaten West Bandung described as follows:

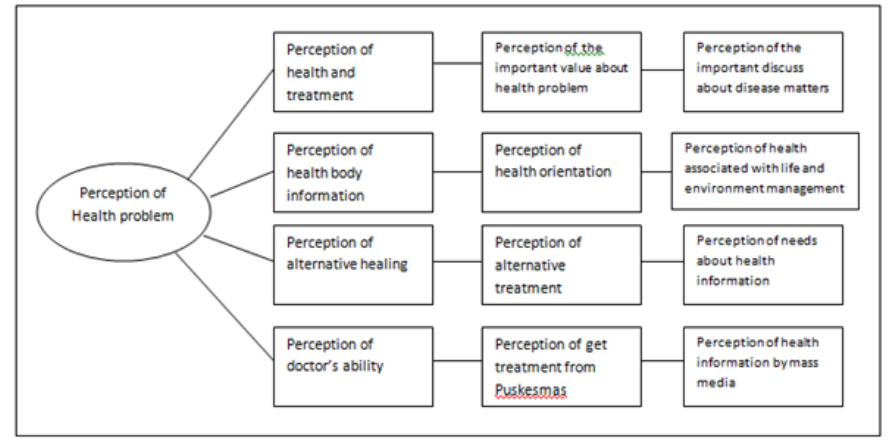

Fig. 1. Perception model of very poor household health problem

\section{B. Discussion}

The phenomenon of poor household orientation (RTSM) to health communication involves many factors. In this study is expressed in 12 perceptions related to it. If studied further, the 12 aspects have relevance to some theories that explain the determinants of health behavior, namely Lawrence Green theory, Snehandu B. Karr theory, and WHO theory.

Lawrence Green's theory argues that there are two determinants of health problems, namely behavioral factors, and non-behavioral factors. Behavioral factors, according to this theory are determined by three main factors, namely: (a) the factors of predisposition (disposing factors), namely the factors that facilitate or predispose to the behavior of a person, including knowledge, attitudes, faiths, beliefs, values, traditions, and so on; (b) enabling factors, i.e. factors that enable or facilitate behavior or action, (c) reinforcing factors, are factors that encourage or reinforce behavior. In Snehandu B. Karr's theory, it is argued that there are 5 determinants of health behavior, namely: first, the intention of a person to act in connection with the object or stimulus from outside himself, secondly, the support of the surrounding community (social support) accessibility of information, i.e. the availability of information related to the action to be taken, fourth, the existence of autonomy or personal autonomy to make decisions, and fifth, the existence of situational conditions and situations (action situations), that to act, necessary to have appropriate conditions and situations. In WHO theory, it is proposed that there are factors influencing health behavior, namely (1) thoughts and feelings, which the result of personal consideration to the object or stimulus is the initial capital to act or behave, (2) the existence of references from an individual or a person who is trusted (personal references), (3) available resources are supporters for the behavior of a person or society, and (4) a local social culture that influences the formation of a person's behavior [7].

Poor condition that affects a person, is related to the health behavior of the person. The conditions of the people and/or the poor are described as follows: (a) the community is unable to meet basic consumption needs such as clothing, food and shelter, inability and limitations to access other basic needs such as health, education, sanitation, clean water, and others; (b) there is no future guarantee, because not being able to invest in education, health and others; (c) the life is vulnerable to the problems of life faced, both individually and /group mass (d) the quality of human resources and natural resources is relatively low, (e) involvement in social activities is relatively low, because of low self-esteem, (f) access to sustainable employment and livelihoods is limited, because of very limited skills, (g) the ability to work is limited, due to the physical and mental condition of the disability, (h) social disadvantage, such as the state of abandoned children, women victims of violence in the household, poor widows, and marginal and remote groups.

Another picture of the poor is proposed by Mardimin (1996) that the poor can be caused by human factors and nonhuman factors. The causes of human poverty include: (a) attitude, mindset, low insight, lazy thinking and work, (b) very limited skills and competences, (c) apathetic and pessimistic in facing life. (d) feel low self-esteem when facing others, (e) very low level of education, (f) not so concerned with the waste of time, to perform less useful activities, $(\mathrm{g})$ no motivation for self-development and achievement, (h) lack of motivation for cooperation both in social activities and in business activities, (i) legal and political awareness is still low, (j) The existence of shackles of customs and habits that limit the public space for productive, (j) the distance of material ownership between rich and poor are so wide that the poor are not able to access the sources of income freely, because they are controlled by the rich $(\mathrm{k})$ a very dense population so that the access to sources of 
income competes strictly, (l) the large number of unemployed people and the limited employment, $(\mathrm{m})$ the inability to utilize local natural resources and human resources from those with capital and power, (n) the skilled manpower are is small in number so that many activities cannot be done, (o) inability to access technology, because of the limited skills, knowledge and insight.

There are also non-human factors that cause poverty that include: (a) natural factors, such as infertile, barren land, (b) limited transportation facilities, such as heavily damaged roads, or pathways to get to the location, (c) very limited public facilities needed by the community, such as puskesmas, posyandu, financial institutions, etc. (d) very limited capital for community use, so that the community is difficult to do business, (e) the area where the community live is isolated, (f) very low skill level of society, so unable to produce anything that sells, (g) the selling price of agricultural produce is very low, so that people do not benefit from their efforts, (h) technological scarcity as a result of low adoption rates of community innovation, (i) very low information access due to very low purchasing power, so that the society do not know the progress that happened in all aspects (j) less active and initiative from existing social institutions, resulting in very little coaching/training given to society, $(\mathrm{k})$ inequality of land ownership, where on the one hand there is a very wide ownership, but on the other hand there is a zero or very narrow ownership, thus implicating the increasingly gap between rich and poor [8].

In this study, although the respondents were very poor, the orientation towards health communication showed some concern. Health communication is a part of interpersonal communication that focuses on how an individual in a group/society faces health-related issues and tries to maintain their health [7]. Health communication as "Health Communication is a multifaceted and multidisciplinary approach to reach different audiences and share health-related information with the goal of influencing, engaging, and supporting individuals, communities, health professionals, special groups [9]. The focus in healthcare communication is the specific transaction on the issues that the healthcare professionals are facing, related to health and the factors influencing the transaction [7]. Transactions that take place between health experts and between health professionals and clients are a major concern in healthcare communication.
Based on the results of this study, it was found that very poor households (RTSM) located in West Bandung area showed the presence of a desire to live healthy through existing patterns and looked for other ways that could be viewed to be able to facilitate their health needs.

\section{CONCLUSION}

The perception of very poor households (RTSM) on health problems as a whole is in the medium category. Aspects related to RTSM's perception of health problems include the following aspects: (1) perception of illness and treatment, (2) perception of healthy body information, (3) perception of alternative healing, (4) perception of physician/doctors' ability (6) perceptions of the importance of health problems, (6) perceptions of health orientation, (7) perceptions of alternative health treatment, (8) perceptions of treatment to health centers, (9) perceptions of the importance of disease discussion, (10) perceptions of health related to the management of life and the environment, (11) perception of health information needs, and (12) perception of health information through mass media.

\section{ACKNOWLEDGMENT}

Acknowledgments are conveyed to all leaders of Universitas Padjadjaran who have funded the Academic Leader Grand (ALG) research, which this article is one part of the research undertaken.

\section{REFERENCES}

[1] World Health Organization (WHO), Definisi Sehat. [cited 201620 February]. Available from: www.who.int., 1947.

[2] Undang-Undang No. 36 Tahun 2009 tentang kesehatan

[3] M. Mu'rifah, Materi Pokok Pendidikan Kesehatan. Jakarta: Universitas Terbuka, 2007.

[4] Badan Pusat Statistik (BPS), Data dan Informasi Kemiskinan kabupaten Kota. Jakarta: BPS, 2011.

[5] S. Djoko and H. Muliawan, Dasar-Dasar Pengantar Ekonomi Pembangunan. Jakarta: PT. PP. Mardi Mulya, 2009.

[6] Badan Pusat Statistik kabupaten Bandung Barat. 2016

[7] N. Soekijo, Promosi Kesehatan, Teori dan Aplikasi. Jakarta: Rineka Cipta 2005.

[8] M. Manurung, Manajemen Keluarga. Bandung: Indonesia Publishing House, 1995.

[9] S. Renata, Health Communication. From Theory to Practice. United States: John Willey and Sons, 2007. 